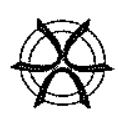

PLANNING MALAYSIA

Journal of the Malaysian Institute of Planners (2004) II, 1-10

\title{
CREATING THE ESSENCE OF CITIES: THE PUTRAJAYA'S EXPERIENCE
}

\author{
Jebasingam Issace John \\ City Planning Department \\ PUTRAJAYA CORPORATION
}

\begin{abstract}
The creation of a new Federal Government Administrative Centre at Putrajaya marks a new chapter in the development history of modern Malaysia. The development of this new administrative centre was prompted by the need to balance and disperse development to areas outside of Klang Valley. It is a decision motivated by the government's desire to improve the urban environment and quality of life, and to ease the pressure on the infrastructure in Kuala Lumpur and the Klang Valley in general. In city planning terms, it provides a golden opportunity and a challenge to embark on something new and innovative representing Malaysian values and culture. Putrajaya the new Federal Government Administrative Centre, is to be equipped with the latest facilities and technologies for improved effectiveness and productivity, as well as, amenities that shall contribute to quality living and working environment. However the challenge also lies in fostering the spirit, sense of purpose and identity for the new city. This paper provides an insight to some of the basic principles and concepts behind the endeavor towards realizing this planning vision.
\end{abstract}

Keywords: Garden City, Urban Design, Quality Urban Living, Caring City

\section{INTRODUCTION}

\section{Background to the Planning Process}

On $2^{\text {nd }}$ June 1993 the Federal Government decided on an area in Perang Besar, Sepang, Selangor Darul Ehsan to be the site for the new Federal Government Administrative Centre. Thereafter, the planning process for Putrajaya went into full swing with the setting up of Putrajaya Development Committee and the Putrajaya Development Unit within the Prime Minister's Department. In 1994, five alternative concept schemes by local consultants and a group of government agencies led by the Federal Department of Town and Country Planning and the Public Works Department were presented to the Cabinet. Of the five schemes, the Government selected the "Garden City" concept as the guiding theme for the new city. A master plan was subsequently developed 
based on this theme. The Putrajaya Master Plan was given Government approval in February 1995. It later underwent a review upon which a final approval was obtained in April 1997. To implement the plan, Perbadanan Putrajaya (Putrajaya Corporation) was established in 1996 with the main role of developing, managing and administration of the city area. Putrajaya Holdings Sdn. Bhd., a government-owned company, was also formed to act as the master developer responsible for construction of government offices, commercial areas, residential premises and the main infrastructure.

\section{PUTRAJAYA MASTER PLAN}

The Putrajaya Master Plan covers an area of approximately 4,600 hectares. The Garden City concept is clearly evident in the amount of land area dedicated to open space within the city, which is $1,826.5$ hectares $(37.0 \%)$. In brief, the major features of the Master Plan are:

i. A large proportion of the city area is designated as green open space;

ii. A large water body (man-made lake) and wetlands was formed by utilizing the small rivers which run through the area;

iii. The lake created a 38 kilometers long waterfront area;

iv. The city is divided into 20 precincts with the 'core employment and commercial precincts' (Core Area) located on an island within the man-made lake;

v. 'Peripheral' (residential) precincts planned based on the neighbourhood planning concept to accommodate a mix of residential, neighborhood commercial, and public amenities;

vi. A $4.2 \mathrm{~km}$ long boulevard forms the central spine of the city;

vii. Projected residential population of 330,000 ; with 67,000 housing units;

viii. The Master Plan is supplemented with urban design guidelines, policy documents, and local plans prepared to meet statutory requirements. 
TABLE 1:

Master Plan Land Use Components

\begin{tabular}{|l|c|c|}
\hline Land Use & Hectares & \\
\hline Government & \% \\
\hline Commercial & 284.6 & 5.8 \\
\hline Housing & 139.4 & 2.8 \\
\hline Civic \& Cultural & $1,173.7$ & 23.8 \\
\hline Public Facilities & 10.6 & 0.2 \\
\hline Utility \& Infrastructure & 452.0 & 9.2 \\
\hline Open Space & 1044.2 & 21.2 \\
\hline Y Total & $1,826.5$ & 37.0 \\
\hline
\end{tabular}

\section{CREATING THE ESSENCE OF CITIES}

The main function of town planning as argued by Foley is to provide a good physical environment, essential for the promotion of a healthy and civilized life. Given that improvement in quality of life is the Government's underlying aim for developing Putrajaya, the city planners have been quick to take the cue by making "quality urban living" as the basic objective for planning Putrajaya. This explains the adoption of the Garden City concept for guiding its physical development. The intention is not only to create a city where social activities take place within an ideal landscape where nature permeates into all aspects of life, but also one which would display a combination of the following features:

- Efficient accessibility to amenities, services and places of work

- Integrated Neighbourhood and community atmosphere

- Proximity to nature

- Ample facilities for recreation

- Dynamic, lively and economic vitality

- A city with identity and character

- Conducive Urban Environment for quality \& healthy Life-style

Through careful planning - supported by good urban management and governance - these concepts were translated physically, complemented by appropriate social, environmental and economic programs, and in the process created the essence of the city that is Putrajaya. 


\section{QUALITY URBAN LIVING THROUGH NEIGHBOURHOOD PLANNING}

Quality urban living involves more than just providing places of work and residence. If we examine on other cities with proven reputation for high urban quality of life, essential ingredients would include facilities and amenities for individual fulfillment and community life, i.e. for cultural, recreational, social interaction and other activities. In Putrajaya, the planners have been ever mindful of the fact that we are not just building an administrative centre; we are trying to build a new community. Meeting the various socio-cultural needs of the inhabitants is therefore a top priority.

Foremost in priority is of course adequate and suitable housing. A broad mix of residential development type is planned for the city including luxury bungalows, semi-detached and terrace-type housing, condominiums, apartments and affordable housing for the lower income group. This brings people of diverse age, races, and income to Putrajaya, strengthening the personal and civic bonds essential to build a new community. The residential development is further enhanced by having mixed land use to encourage multi-functions in close juxtaposition. The outcome is a neighbourhood with a variety of urban amenities for worshiping, shopping, health, learning, sports and recreation, and even working. In close proximity, are community facilities such as Suraus (places of worship), convenience shops, clinics, schools, multi-purpose halls, markets and local parks are provided. In line with the Garden City theme, a large proportion of the city area is designated as parks and open spaces ranging from metropolitan parks to local neighbourhood playgrounds. Reinforcing these facilities are urban features such as landmarks, squares, plazas and bridges that form part of the cityscape, providing a wide range of spatial experiences that further enhance the spatial quality of the city. Connecting these nodes are some carefully planned safe streets and pedestrian routes which is from interesting part of the urban feature that function as space for 'face-to-face' interaction. The planners are ever mindful of Lewis Mumford's warning that 'we need to make sure we don't make the city more attractive to vehicles temporarily and infinitely less attractive to human beings permanently'.

What is significant in Putrajaya is that all these amenities and facilities are found in close proximity to the residents which is achieved through the adoption of the neighbourhood concept in the planning of its residential precincts. The size of the neighborhood is such that a majority of the population is within a five-minutes walking distance of its center $(1 / 4$ mile) and where the needs of daily life are mostly available within this area. These reduce the number and 
length of automobile trips, and conserve energy. It also expands transportation choices where people can not or do not have to drive.

All these are of concern around the urban development scenario in other countries too. In 1994 the Equitable Real Estate Investment Management Inc in their annual report entitled 'Emerging Trends' were of the view that;

"For the future we believe the premier investments will be in the nation's 24 hour cities. These markets whether urban or suburban are places where people can comfortably and securely live, work and shop............. attractive neighbourhoods lie within hailing distance of the office, and at the very least you don't have to spend a major fraction of your life commuting to work. It's a short walk to take the kids to the park. The supermarket is within easy reach, you can pick up a litre of milk any time........Mass transit also helps the success of an area...." The planning of Putrajaya has been done with great understanding and awareness that we hope to build a city where "people live where they work, work where they shop and shop where they live."

\section{REVISITING THE TRADITIONAL ESSENCE: FOSTERING THE SPIRIT AND PURPOSAL OF THE CITY}

When we talk about traditionalism the precise meaning of traditional is important. The Latin root 'traditio' means to bring across; to offer guidance from the past into the present. At times, cities are defined as places where everyone is a stranger, whereas villages (kampung) are places where they know each other. If there was a difference between the traditional kampung way of life of yesteryears and the present day city life-style, it is in the citizen's spirit and sense of togetherness. In Putrajaya, there is an attempt to foster the essence of cities by reference to past land use, spatially relationships and urban form as they might be influenced by local history and culture. It seeks to rediscover and recreate the interactive, spatial efficient and robust qualities of a coherent public realm that earlier urban environments, small towns and villages exhibited most often characterized by an informal, organic layout, a strong sense of community and close proximity to the surrounding natural environment. Whilst it is not practical to recreate the kampung within the constraints of our cities today, we can still establish the planning principles to foster social and community values associated with traditional kampung living. The objective is to encourage a more pervasive involvement of the residents in activities contributing to the well being of the community. The neighbourhood concept of planning plays a great role here whereby the layout of residential areas and location of amenities 
can encourage greater interaction and a sense of neighbourliness among residents.

This may be achieved by influencing the scale, density, form, and structure of urban development. For example streets can be designed to be human-friendly and equitable for both vehicles and pedestrians where people can interact on the streets. Streets in Putrajaya are safe, comfortable, interesting places for people to walk and meet. Most of the buildings open onto sidewalks, rather than parking lots. Windows and doors facing the sidewalk make streets safer, and more interesting, for everyone. Urban spaces in the form of public squares or public parks and fields should also become a meeting place and centre for various community related activities. Nevertheless needs of daily life should be available at the neighbourhood centre within the residential area where people congregate and meet their neighbours. This approach to planning is adopted in most of Putrajaya residential areas, most notably in the design of the Diplomatic Enclave.

\section{THE CARING CITY}

Building a city is not just about bricks and mortar. To complement the promotion of the 'traditional essence', pro-active efforts are also necessary to consolidate the sense of community and belonging. For this, consensus through public engagement and outreach activities are carried out in Putrajaya. Programs based on the 'Caring City' and 'Safe City' concepts are being explored and applied.

This is further aided through conscious design efforts as reflected in the Putrajaya Fencing Design Guideline which draws on our culture to create a safe city. This is by encouraging interaction and a caring society through community-policing and "permeability" in development, i.e. the breaking down of walls.

In general, solid fencing along streets and other boundary frontages is discouraged. In its place, permeable fencing options are preferable. This shall be mainly through the use of landscape demarcations such as hedges, shrubs or trees. These solutions contribute to the aesthetic, social and built form character of Putrajaya. More importantly, it enhances security through increased interaction and proactive community involvement and responsibility, as opposed to perpetuating an individualistic island mentality. 


\section{CITY IMAGE AND CHARACTER THROUGH URBAN DESIGN AND LANDSCAPE ARCHITECTURE}

Building a new city is a monumental task requiring the input of various groups of people with diverse disciplines. Guided by the Garden city concept, and with the aim of achieving a strong image for the city, urban design and landscape architecture are established as essential ingredients complementing good town planning practices.

Urban design is the art of city building (Moughtin et al). It deals with the way places work and how urban spaces are organized and structured. Closely related, landscape architecture is concerned with the design and shaping of external spaces, treating the 'public realm' as part of the total built environment and city experience. In Putrajaya, effort towards good urban design and landscape planning is achieved through the use of the Detailed Urban Design guidelines (DUD).

The DUD is prepared at the precinct level. It outlines the general character and ambience of each particular development plot, but always at the same time, tying it back to the surrounding development parcels and the precinct as a whole. By this, the DUD promotes an urban fabric and language through the composition of its many elements, combining them to reflect a unique sense of place and character.

The DUD achieves this by focusing on elemental guiding principles such as urban structure, urban form and character. Parameters like details on land use, building massing and typology, horizontal and vertical controls of building, provision for pedestrian linkages, open space coverage, streetscape control and so on feature highly in this guideline. The aim is to create towards an urban form that projects visual unity and coherence, affording a distinctive image for the city and quality spatial experience for citizens and visitors alike.

The DUD is now used to create identifiable urban spaces and corridors such as the Putrajaya Boulevard and the Dataran Putrajaya where the National Day Merdeka Parade was held in 2003 . The Boulevard is a $4.2 \mathrm{~km}$ long $100 \mathrm{~m}$ wide thoroughfare running from North to South of the Core Island forming the central spine of the city and providing the setting for the main commercial and civic area. The design parameters for the buildings along and in proximity to it are guided by the DUD so that they contribute to a cohesive spatial composition and experience of the Boulevard. 
As an extension to the effort of creating an image and character for the city, the Putrajaya Lighting Master Plan has also been formulated to establish the visual and practical architectural lighting criteria that will ensure the night time ambience of Putrajaya is attractive and appropriate of a city of its status and function. It is a unique effort, and it is hoped that this will contribute to bringing more visitors and tourists to come and enjoy Putrajaya during the night.

\section{RESPECT FOR PEDESTRIANS}

The advent of the motor car signaled the overriding importance given to the convenience of the motor traffic over that for pedestrians. This is despite the fact that motor car users - upon reaching their destination, would themselves become pedestrians. This was the scenario which perhaps led Mumford to lament "As soon as the motor car become common, the pedestrian scale of the suburb disappeared, and with it, most of its individuality and charm". Mumford also said "The paradoxical result of this concentration on motorcars is a curbing of freedom of movement, a removal of alternate choices of transportation, the steady reduction of the speed of local travel, and the total defeat of the city itself as a place that offers the maximum possibilities for face-to-face meeting, social cooperation, and transactions of every kind".

Successful cities are about the inter-relationship between wholes and parts. To achieve that Putrajaya has been designed to respect pedestrians. Provision for pedestrians and cyclists increases independence of movement and accessibility to the numerous facilities in the city without resorting to motorized vehicles. It is also compatible with planning for public transport systems. Pedestrian routes in Putrajaya are laid out across the city in an integrated manner. They link major activity centres and nodes such as government precincts, commercial centres, public parks, plazas, community centres and schools together. They also provide clear and direct access to transit stops as well as connections between residential and retail areas.

Supportive urban design is the key to encouraging the usage of pedestrian and cycling facilities. DUD guidelines for core areas identify pedestrian routes and connections throughout each precinct and at each parcel development level. Pedestrian paths are supported by facilities such as arterial crossings where necessary. Landscape treatments are specified for each development parcel to provide shade and comfort for pedestrians. Particular emphasis is given to ease of movement of pedestrians and cyclists through careful consideration to gradient of the paths, 'barrier free' designs and coordinated network of paths. 


\section{URBAN ECOLOGY: NATURE IN THE URBAN FABRIC}

One of the requisites for a quality urban living environment is to create a city in harmony with nature, i.e. a city which contains natural elements within its urban fabric and one which imposes minimum stress onto the ecosystems. This will not only ensure the long-term sustainable development of the city, but it brings opportunities for recreation and for being close with nature.

Perhaps the most significant effort towards this in Putrajaya is the creation of a water body in the form of a lake and wetlands systems. About 600 hectares or $12 \%$ of Putrajaya's consists of lakes and wetlands. The lake is formed by damming Sg. Chuau and Sg. Bisa which passes through the city. The wetland is the first man-made wetlands in Malaysia and one of the largest fully constructed freshwater wetlands in the tropics. Among others, it functions as a natural filtration system removing nutrients and pollutants from the river water before it enters the lake.

The lake and wetlands have turned out to be one of the most valuable assets for Putrajaya. It has brought about intangible values in the unique waterfront image and character of the city. In fact Putrajaya can be considered as a waterfront city bearing the following features and opportunities:

- Development opportunities in prime waterfront location affording a rich mix of development;

- Existence of wetlands, green corridors, parks, and wildlife at the door step of urban dwellers; and

- A range of water recreation and sports activities opportunities.

The 38 kilometers of waterfront area created with the formation of the lake is utilized for development of parks and promenade, i.e. - an integrated network of green spine which connects all the lakefront parks together. It is provided with a whole range of facilities to enhance their enjoyment by the public such as landscaped walkways, seating areas, public beaches, fishing piers, and viewing decks.

With the parks and greenery come wildlife and nature experience. Certain stretches of the promenade and walkways - such as those within the Taman Wetland - have been designed as nature trails providing for people to reconnect with nature. The lakefront parks, including the wetlands, have been successful in introducing a range of habitats for fish, invertebrates, frogs, turtles, as well as, birds such as swifts, moor hens, water hens, wild ducks and kingfishers. In 
short, nature and open spaces are as important to Putrajaya as the garden is to the house.

\section{CONCLUDING REMARKS}

Town planning is about urban quality of life. In our surge towards a developed nation status, it is crucial that we do not lose sight of the very objectives of planning and the basic principles of good city planning that go with it. This is important, lest we become an affluent yet faceless society, devoid of selffulfillment, no sense of community, and with the ever-present physical and social problems. This is why in the planning for Putrajaya, we have strived to go back to identifying and creating the essence of cities and trying to answer: what is essential in town-making? The planning of Putrajaya rediscovers and adapts to the principles of traditional urbanism. These principles are more interactive, spatially efficient, as well as environmentally and socially positive.

\section{ACKNOWLEDGEMENT}

This paper is prepared with the assistance of En. Azizi Ahmad Termizi, Deputy Director and Mr. Ho Lip Wah, Assistant Director (Town Planning), City Planning Department, Perbadanan Putrajaya. 